\title{
Cerebrospinal Fluid Biogenic Amines in Obsessive Compulsive Disorder, Tourette's Syndrome, and Healthy Controls
}

James F. Leckman, M.D., Wayne K. Goodman, M.D., George M. Anderson, Ph.D., Mark A. Riddle, M.D., Phillip B. Chappell, M.D., Maureen T. McSwiggan-Hardin, M.S.N., Christopher J. McDougle, M.D., Lawrence D. Scahill, M.S.N., M.P.H., Sharon I. Ort, M.P.H., David L. Pauls, Ph.D., Donald I. Cohen, M.D., and Lawrence H. Price, M.D.

To examine the role of noradrenergic, dopaminergic, and serotonergic mechanisms in the pathobiology of obsessive compulsive disorder (OCD) and Tourette's syndrome (TS), concentrations of tyrosine (TYR), norepinephrine (NE), 3-methoxy-4-hydroxyphenylethylene glycol (MHPG), homovanillic acid (HVA), tryptophan (TRP), and 5-hydroxyindoleacetic acid (5-HIAA) were measured in the lumbar cerebrospinal fluid (CSF) of 39 medicationfree OCD patients, 33 medication-free TS patients, and 44 healthy volunteers. CSF TYR concentrations were reduced $(\mathrm{p}<.05)$ in the OCD patients compared to the healthy subjects. CSF NE in TS patients was 55\% higher than in healthy controls $(\mathrm{p}<.001)$ and $35 \%$ higher than in OCD patients ( $\mathrm{p}<.001)$. After covarying for height, CSF HVA levels were reduced ( $\mathrm{p}<$ $.05)$ in the OCD group compared to TS patients but not compared to the normal volunteers. No mean differences in CSF MHPG, TRP, and 5-HIAA were observed in this study across the three groups. The CSF NE data support the hypothesis that noradrenergic mechanisms are involved in the pathobiology of TS. Alterations in the balance of noradrenergic, dopaminergic, and serotonergic systems are likely involved in the pathobiology of OCD. [Neuropsychopharmacology 12:73-86, 1995]
KEY WORDS: Obsessive compulsive disorder; Tourette's syndrome; CSF; tyrosine; norepinephrine; 3-methoxy-4hydroxyphenylethylene glycol; homovanillic acid; tryptophan; 5-hydroxyindoleacetic acid

From the Child Study Center (JFL, GMA, PBC, CJM, LDS, SIO, DLP, DJC), Departments of Psychiatry (JFL, CJM, LHP, DJC), Genetics (DLP), and Pediatrics (JFL, DJC), Yale University School of Medicine, New Haven, Connecticut; and General Clinical Research Centers, Yale-New Haven Hospital, New Haven, Connecticut (JFL, GMA, PBC, DLP, DJC, LDS, SIO); Clinical Neuroscience Research Unit Abraham Ribicoff Research Facilities, Connecticut Mental Health Center, New Haven, Connecticut (LHP, CJM); Departments of Psychiatry, University of Florida College of Medicine, Gainesville, Florida (WKG); Department of Psychiatry and Behavioral Science, Johns Hopkins Medical Institutions, Baltimore, Maryland (MAR); and Department of Psychiatry, Medical College of Georgia, Augusta, Georgia (MTM). Address correspondence to: James F. Leckman, Child Study Center, 230 S. Frontage Road, P.O. Box 207900, New Haven, CT 06520-7900.

Received April 18, 1994; revised August 31, 1994; accepted September 8, 1994.
Obsessive compulsive disorder (OCD) is a chronic neuropsychiatric condition characterized by recurrent and disturbing thoughts (obsessions) and/or repetitive, relatively stereotyped, behaviors that an individual feels driven to perform (compulsions). In a subset of earlyonset OCD patients, the course of illness is complicated by a chronic tic disorder (Pitman et al. 1987; Leonard et al. 1993). Tourette's syndrome (TS) is a chronic neuropsychiatric disorder of childhood onset that is characterized by tics that wax and wane in severity and by an array of associated behavioral problems, including attention deficit hyperactivity disorder (ADHD) and obsessive compulsive disorder (OCD) (Robertson 1989; Leckman et al. 1992). Family-genetic studies further suggest OCD may be etiologically heterogenous with some forms related to TS (Pauls and Leckman 1986; Pauls et al. 1991).

Although a number of neurotransmitter and neu- 
romodulatory systems are likely to be involved in the pathobiology of $O C D$, the strongest evidence concerns the role of serotonergic projections that modulate the activity of the basal ganglia and functionally related cortical and thalamic structures (Insel 1992). The effectiveness of potent or selective serotonin reuptake inhibitors (SSRIs) such as clomipramine (Clomipramine Study Group 1991), fluvoxamine (Goodman et al. 1989a, 1990a), fluoxetine (Pigott et al. 1990), and sertraline (Chouinard et al. 1990) in producing clinical improvement in $40 \%$ to $60 \%$ of OCD patients is noteworthy in this regard. However, a substantial number of OCD patients do not respond to these agents or experience only modest benefit. One factor that may influence the effectiveness of SSRIs in OCD is whether the patient has a personal history of TS or another chronic tic disorder. For example, McDougle et al. (1993) reported that OCD patients with a comorbid chronic tic disorder showed only a $21 \%$ response rate to fluvoxamine compared to a $52 \%$ response rate in OCD patients without chronic tics.

Although dopaminergic mechanisms have been implicated in the pathobiology of TS (see Leckman et al. in press-a and Singer, 1993 for reviews), the role of brain dopaminergic systems in OCD has not been carefully studied despite preclinical and clinical data implicating these systems (see Goodman et al. 1990b for a review). Several studies have suggested that tic-related $O C D$ can be distinguished from non-tic-related OCD on the basis of treatment response. For example, McDougle et al. $(1990,1994)$ found that haloperidol in addition to ongoing SSRI treatment in fluvoxaminerefractory OCD patients was preferentially effective in OCD patients with comorbid tics compared with ticfree OCD patients. Hanna et al. (1991) reached a similar conclusion after finding higher levels of plasma prolactin in OCD patients with a either a positive personal or family history of chronic tics compared to non-tic-related OCD patients. This increase was observed under both basal conditions ( $50 \%$ higher) and post 8 weeks of clomipramine ( $40 \%$ higher). Taken together, these psychopharmacological and neuroendocrine data are consistent with an altered balance of serotonergic and dopaminergic tone in $O C D$ patients with comorbid tics compared to tic-free OCD patients.

Evidence of noradrenergic involvement in the pathophysiology of TS is based in part on the reported beneficial effects of the $\alpha_{2}$ adrenergic agonist clonidine (Cohen et al. 1979). Although the effectiveness of clonidine remains controversial (Goetz et al. 1987), several clinical trials provide evidence of a beneficial effect of this agent on motor tics and some of the symptoms of ADHD (McKeith et al. 1981; Borison et al. 1983; Leckman et al. 1991a). Additional support has been based on the rebound exacerbations of tics in patients abruptly withdrawn from clonidine (Leckman et al. 1986), and on the finding of a blunted growth hormone response to clonidine challenge in children and adults (Leckman et al. 1984; Müller et al. 1994) with TS. Most recently, a series of adult TS patients was found to have high levels of urinary NE excretion in response to the stress of lumbar puncture (LP) (Chappell et al. 1994). Studies of central and peripheral levels of 3-methoxy-4-hydroxyphenylethylene glycol (MHPG), a major metabolite of NE, have been inconclusive (Cohen et al. 1978; Butler et al. 1979; Ang et al. 1982; Singer et al. 1982; Leckman et al. 1988; Bornstein and Baker 1992). In addition, no differences in platelet $\alpha_{2}$ adrenoreceptors (Silverstein et al. 1985) or in plasma NE (Lake et al. 1977) have been found.

In open-labeled studies, clonidine has also been reported to improve obsessive compulsive (OC) symptoms (Knesevich 1982; Hollander et al. 1988, 1991), but this effect may be transient (Hollander et al. 1988). No improvement in OC symptoms was observed in a largescale clinical trial of clonidine in a group of TS patients (Leckman et al. 1991a). In blind comparisons with serotonin reuptake blocking agents, NE reuptake blockers have not been shown to be effective in the treatment of OCD (Zohar and Insel 1987; Leonard et al. 1989; Goodman et al. 1990a). Other studies have attempted to evaluate the role of noradrenergic systems in OCD with the use of challenge paradigms that either seek to stimulate or block $\alpha_{2}$ NE receptors, but the results have been inconclusive (Siever et al. 1983; Rasmussen et al. 1987; Hollander et al. 1988; Lee et al. 1990).

With one exception (Swedo et al. 1992), previously reported CSF studies of biogenic amines have not addressed the potential differences between OCD patients with versus without a personal or family history of a tic disorder (Thorén et al. 1980; Insel et al. 1985; Lydiard et al. 1990). In addition, none of the available CSF reports include sizable numbers of both $O C D$ and TS patients in the same study. None of the prior CSF studies of OCD reported concentrations of the amino acid precursors tyrosine (TYR) and tryptophan (TRP), nor did they measure CSF levels of norepinephrine (NE). Prior CSF studies of biogenic amines in TS have yielded inconclusive results and have been limited by small sample sizes (Cohen et al. 1978; Butler et al. 1979; Leckman et al. 1988) and a failure to examine the effects of comorbid OCD (Cohen et al. 1978; Butler et al. 1979).

As part of a comprehensive study of monoamines, precursors, and metabolites, we measured the lumbar CSF concentrations of TYR; NE; MHPG; homovanillic acid (HVA), a major CNS metabolite of dopamine and a minor metabolite of NE; tryptophan (TRP); and 5-hydroxyindoleacetic acid (5-HIAA), the major central metabolic of serotonin, in TS and OCD patients and in a group of healthy controls. We hypothesized that OCD patients with comorbid tic disorders would more closely resemble (in terms of their neurochemical 
profile) TS patients with concomitant OC symptoms than OCD patients without a personal or family history of chronic tics. We further hypothesized that TS patients, but not OCD patients, would have elevated indices of central noradrenergic function and that these elevations would be more closely associated with the current severity of motor tics than of phonic tics.

\section{SUBJECTS AND PROCEDURES}

\section{Subjects}

CSF was obtained in a standardized fashion from a total of 116 subjects ( 39 patients with OCD, 33 patients with TS, and 44 normal controls). Most of the OCD and normal control subjects were recruited locally within the State of Connecticut. Patients were recruited from a wider geographic area with the help of the national Tourette Syndrome Association (TSA) and local TSA chapters in Connecticut, New York, Massachusetts, Rhode Island, New Jersey, and Pennsylvania. Members of the state TSA organizations were contacted by letter and invited to participate in a range of ongoing studies. Each medication-free member who expressed an interest in participating in a research study was contacted. Preliminary reports concerning this data set have appeared elsewhere (Leckman et al. 1988, 1990b).

Patients were initially diagnosed clinically using DSM-IIIR criteria. Patients and controls, their firstdegree relatives (parents, siblings), and spouses, if available, also completed a semi-structured diagnostic interview based on the Diagnostic Interview Schedule, as previously described (Pauls and Hurst 1987). Final diagnoses were made independently and blindly (with respect to their ascertainment) by two diagnosticians (JFL and DLP) using all available information (Leckman et al. 1982). Prior estimates of the agreement between these two rates using Cohen's kappa coefficient have all been above .90 (indicating excellent agreement) for the diagnoses of TS, OCD, ADHD, and major depression. When diagnostic disagreements arose, a joint review of all materials was performed and a "best estimate" consensus diagnosis was made. In comorbid cases in which an individual received both a diagnosis of OCD and a tic disorder, a "principal diagnosis" was assigned based on the individual's clinical presentation and level of disability associated with each set of symptoms. Based on these diagnostic estimates, five patients were dropped from the study because they were not judged to have a principal diagnosis of either OCD or TS. Seven normal control subjects were found to have a positive family history of either OCD or a tic disorder and were excluded from this sample. In the four- and five-group diagnostic comparisons, the remaining OCD patients were further subdivided into two groups: those with a personal or family history of TS or a chronic tic disor$\operatorname{der}(n=11)$ and those without such a history $(n=28)$. In the five-group diagnostic comparisons, the TS cases were subdivided into those with OCD (TS + OCD, $n=$ 18 ) and those without OCD (TS alone, $n=12$ ).

In the final data set of 104 subjects, there was insufficient lumbar CSF to permit determination of $\mathrm{NE}$ in seven subjects; HVA, TRP, and 5-HIAA in three subjects; TYR in one subject; and MHPG in one subject.

\section{Procedures}

Subjects gave informed consent before participating in the study. Subjects were medication-free for a minimum of 4 weeks (two months in the case of neuroleptics and fluoxetine) prior to the lumbar puncture (LP). All subjects were in good health and received a physical examination, standard hematologic and clinical chemistry studies, urinalysis, and electrocardiogram to screen for medical disorders. Height and weight were recorded at the time of admission. Percent ideal body weight (for height and sex) was transcribed from actuarial tables (Society of Actuaries 1959).

Subjects were asked to adhere to a low monoamine diet for one day prior to the LP. After a carbohydrate breakfast, subjects were placed at bed rest between 7:00 and 8:00 A.M. for 4 to 5 hours prior to the procedure. Vital signs were taken at regular intervals using standard techniques. The last set of vital signs prior to the LP was at 12:00 noon and included supine systolic and diastolic blood pressures plus supine heart rate. At 12:30 P.M., the LP was performed in the lateral decubitus position using the L4-L5 interspace. A total of 11 to $21 \mathrm{ml}$ of CSF was collected. The first $\mathrm{ml}$ was used for clinical studies. The next five $\mathrm{ml}(2$ to $6 \mathrm{ml}$ ) were initially collected in a separate tube, mixed, aliquoted, and used to measure the concentrations of the monoamines, their precursors, and metabolites. Aliquots were frozen at $-70^{\circ}$ to $-80^{\circ} \mathrm{C}$ until they were assayed.

\section{Clinical Ratings}

Patients and controls received an extensive psychiatric evaluation at the time of the LP, including clinician ratings of severity of $O C$ and tic symptoms using the Yale-Brown Obsessive Compulsive Scale (Y-BOCS) (Goodman et al. 1989b, 1989c) and the Yale Global Tic Severity Scale (YGTSS) (Leckman et al. 1989), respectively.

Ratings of depression and anxiety were also evaluated using the clinician-rated Hamilton Depression and Anxiety Scales (HAM-D and HAM-A, respectively) (Hamilton 1959, 1967). The 21-item version of 
the HAM-D scale was modified by omitting the last item on OC symptoms so that scores could range from 0 to 61 . The 14-item HAM-A scale was used, with scores potentially ranging from 0 to 56 . Comorbid psychiatric diagnoses were established using the same best estimate procedures described above for TS and OCD.

\section{Assays for CSF Biogenic Amines}

The concentrations of TYR, HVA, TRP, and 5-HIAA in the CSF were determined by using a previously described sensitive and specific high performance liquid chromatography (HPLC) assay with interassay coefficients of variation of $5 \%$ to $9 \%$ (Anderson et al. 1979; Leckman et al. 1988).

Levels of NE were determined by HPLC following alumina extraction of 0.5 to $2.0 \mathrm{ml}$ of CSF (Anderson et al. 1988). An interassay coefficient of variation for the CSF NE assay of $7.5 \%(n=15)$ was observed for replicate samples, with a detectability limit of less than $25 \mathrm{pg} / \mathrm{ml}(0.15 \mathrm{pmol} / \mathrm{ml})$. The concentration of MHPG in the CSF was determined by HPLC (Anderson et al. 1981) with an interassay coefficient of variation of $6.7 \%$ $(n=12)$ and a limit of detectability of less than $1 \mathrm{ng} / \mathrm{ml}$ $(5.43 \mathrm{pmol} / \mathrm{ml})$. All assays were performed blindly to the diagnostic and clinical status of the subjects.

\section{Statistical Analysis}

Taken as a whole, CSF measures of TYR, NE, HVA, and 5-HIAA were not normally distributed. Log transformation of these values resulted in normal distributions for CSF TYR, NE, and HVA. A square root transformation of the CSF 5-HIAA levels yielded a normal distribution. Results are reported as mean \pm one standard deviation. Chi-square, Student's unpaired $t$ test (two-tailed), and general linear models procedures (followed by the Duncan's Multiple Range Tests to account for multiple comparisons) were performed to compare CSF measures across groups. The principal models used to evaluate diagnostic status (an independent class variable) were a three-group model (normals versus OCD versus TS), a four-group model (normal versus non-tic-related $O C D$ versus tic-related $O C D$ versus TS), and a five-group model (normal versus non-tic-related $O C D$ versus tic-related $O C D$ versus $T S+O C D$ versus $T S$ alone). Efforts were made to evaluate the effects of comorbid depression and anxiety by using the comorbid diagnoses (current, past, never) as class variables and by using the current ratings of depression and anxiety as continuous variables in the multivariate analyses. Spearman and Pearson correlation coefficients were calculated, as appropriate, to test for possible associations among variables. In the exploratory analyses, corrections for mul- tiple tests of association (e.g., Bonferroni or Scheffé adjustments) were not employed.

\section{RESULTS}

\section{Sample Characteristics}

Demographic and clinical data on the 104 subjects $(60$ males and 44 females, aged 13 to 63 ) included in this report are presented in Table 1 . As noted, no significant differences with regard to sex, current age, height, weight, or percent of ideal body weight were found comparing the three diagnostic groups.

As expected, ratings of OC symptom severity $(\mathrm{F}[2,99]=107, p<.0001)$ and tic severity $(\mathrm{F}[2,99]=155$, $p<.0001)$ clearly distinguished the three primary diagnostic groups (Table 1). Based on the HAM-D and HAM-A, the overall comparisons across the three diagnostic groups were highly significant for both symptoms of depression $(\mathrm{F}[2,99]=38.2, p<.0001)$ and anxiety $(F[2,78]=47.9, p<.0001)$. Post hoc testing revealed that the OCD patients were significantly more depressed and anxious than the TS patients $(p<.001)$ and that the TS patients in turn were significantly more depressed and anxious $(p<.001)$ than the normal controls (Table 1).

Table 2 presents the frequency of lifetime comorbid psychiatric diagnoses in the two patient groups. High rates of comorbidity for major depression and anxiety disorders were observed in both the TS and the OCD groups. A lifetime diagnosis of ADHD was present in $39 \%$ of the TS patients and $12 \%$ of the OCD patients.

Based on the vital signs collected just prior to the LP, the overall comparisons across the three diagnostic groups was found to be significant for supine heart rate $(F[2,79]=4.09, p=.02)$ but not for supine systolic or diastolic blood pressures. Post hoc testing revealed that the OCD patients on average had a significantly $(p<.05)$ higher heart rate $(78 \pm 14 \mathrm{bpm})$ than the normal controls $(68 \pm 9 \mathrm{bpm})$ with the TS patients falling in between $(71 \pm 14 \mathrm{bpm})$.

\section{Univariate Analyses}

In an effort to identify potentially confounding demographic, physiological, and psychological variables a series of univariate analyses was performed with the entire data set in which current age, height, weight, percent ideal body weight, supine systolic and diastolic blood pressures (obtained just prior to the LP), heart rate, and the clinician ratings of depression and anxiety were correlated with each of the CSF measures. Given the number of analyses, correlations with $p$ values of $<.001$ are needed to be significant using a Bon- 
Table 1. Demographical and Clinical Characteristics

\begin{tabular}{|c|c|c|c|}
\hline & $\begin{array}{l}\text { Normal Controls } \\
\quad(n=35) \\
\end{array}$ & $\begin{array}{l}\text { Tourette's Syndrome } \\
(n=30)\end{array}$ & $\begin{array}{l}\text { Obsessive Compulsive Disorder } \\
\qquad(n=39)\end{array}$ \\
\hline $\operatorname{Sex}(M / F)$ & $22 / 13$ & $21 / 9$ & $17 / 22$ \\
\hline Current age (yrs) & $\begin{array}{c}32.9 \pm 10.6 \\
(19.1 \text { to } 58.2)\end{array}$ & $\begin{array}{c}29.4 \pm 8.2 \\
(13.1 \text { to } 43.6)\end{array}$ & $\begin{array}{l}35.6 \pm 14.1 \\
(18.5 \text { to } 63.1)\end{array}$ \\
\hline Height (cm) & $\begin{array}{l}172 \pm 10 \\
(142 \text { to } 189)\end{array}$ & $\begin{array}{l}175 \pm 10 \\
(157 \text { to } 196)\end{array}$ & $\begin{array}{l}169 \pm 11 \\
(131 \text { to } 188)\end{array}$ \\
\hline Percent ideal body weight $(\%)^{a}$ & $\begin{array}{l}102 \pm 12^{1} \\
(82 \text { to } 137)\end{array}$ & $\begin{array}{l}104 \pm 19 \\
(81 \text { to } 162)\end{array}$ & $\begin{array}{l}100 \pm 13^{2} \\
(79 \text { to } 129)\end{array}$ \\
\hline OC symptom onset (yrs) & & $\begin{array}{l}10.8 \pm 6.9^{3} \\
(2.0 \text { to } 26.0)\end{array}$ & $\begin{array}{l}20.0 \pm 11.1 \\
(2.0 \text { to } 58.0)\end{array}$ \\
\hline OC severity (YBOCS - Total) ${ }^{b}$ & & $\begin{array}{l}12.0 \pm 10.9 \\
(0.0 \text { to } 34.0)\end{array}$ & $\begin{array}{l}25.3 \pm 7.1^{4} \\
(12.0 \text { to } 36.0)\end{array}$ \\
\hline Tic symptom onset (yrs) & & $\begin{array}{l}7.0 \pm 3.1 \\
(3.0 \text { to } 19.0)\end{array}$ & $\begin{array}{l}5.0 \pm 3.6^{5} \\
(2.0 \text { to } 9.0)\end{array}$ \\
\hline Tic severity $\left(\right.$ YGTSS) $^{c}$ & & $\begin{array}{l}49.9 \pm 18.9^{7} \\
(8.0 \text { to } 84.0)\end{array}$ & $\begin{array}{l}9.8 \pm 13.5 \\
(0.0 \text { to } 34.0)\end{array}$ \\
\hline Severity of anxiety (HAM-A) ${ }^{d}$ & $\begin{array}{r}0.7 \pm 1.5^{8} \\
(0.0 \text { to } 8.0)\end{array}$ & $\begin{array}{l}8.6 \pm 6.1^{9} \\
(0.0 \text { to } 21.0)\end{array}$ & $\begin{array}{l}14.2 \pm 7.0^{8} \\
(1.0 \text { to } 29.0)\end{array}$ \\
\hline Severity of depression (HAM-D) ${ }^{e}$ & $\begin{array}{c}0.9 \pm 1.8 \\
(0.0 \text { to } 8.0)\end{array}$ & $\begin{array}{l}10.3 \pm 9.5^{10} \\
(0.0 \text { to } 34.0)\end{array}$ & $\begin{array}{l}16.2 \pm 9.0^{4} \\
(0.0 \text { to } 38.0)\end{array}$ \\
\hline
\end{tabular}

${ }^{a}$ Ideal body weight based on age, sex, and height; ${ }^{b}$ Yale-Brown Obsessive Compulsive Scale; ${ }^{c}$ Yale Global Tic Severity Scale; ${ }^{d}$ Hamilton Depression Scale (21 item version modified to exclude the last item on OC symptoms; ${ }^{e}$ Hamilton Anxiety Scale (14 item).

${ }^{1} n=34,{ }^{2} n=26,{ }^{3} n=16,{ }^{4} n=38,{ }^{5} n=4,{ }^{6} n=6,{ }^{7} n=27,{ }^{8} n=30,{ }^{9} n=21,{ }^{10} n=29$.

ferroni adjustment. Using this threshold, none of these correlations were significant. Using a $p<.05$ threshold, log transformed CSF TYR was correlated with current age $(r=.23, p<.02)$ and inversely correlated with the HAM-A ratings of anxiety $(r=-.30, p<.01) ; \log$ transformed CSF NE was correlated with supine and diastolic $(r=23, p=.05)$ blood pressures measured prior to the LP; CSF MHPG was correlated with percent ideal body weight $(r=.28, p=.007)$; and both log transformed CSF HVA $(r=-.23, p<.02)$ and square-root transformed CSF 5-HIAA $(r=-.27, p<$ $.01)$ were inversely correlated with height. No significant correlations were observed with either weight or heart rate at the time of the LP for any of the CSF measures.

A second group of analyses was performed to examine the potentially confounding effects of sex and comorbidity with either major depression (current, past, never) or generalized anxiety disorder (GAD) (current, past, never). No sex differences were observed for any of the CSF measures. None of the CSF measures differed based on the subjects' history of major depression. Only CSF TRP was found to differ depending on the subjects' status concerning $\operatorname{GAD}(\mathrm{F}(2,85)=5.28$, $p<.007)$ with the 12 subjects with a current diagnosis of GAD having $21 \%$ higher levels $(p<.05)$ of CSF TRP

Table 2. Current and Lifetime Comorbid DMS-IIIR Psychiatric Diagnoses for TS and OCD Groups

\begin{tabular}{lcc}
\hline & \multicolumn{2}{c}{ Primary Diagnosis } \\
\cline { 2 - 3 } Comorbid Diagnosis & $\begin{array}{c}\text { Tourette's Syndrome }(\boldsymbol{n}=\mathbf{3 0}) \\
\boldsymbol{n}(\%)\end{array}$ & $\begin{array}{c}\text { Obsessive Compulsive Disorder }(\boldsymbol{n}=\mathbf{3 9}) \\
\boldsymbol{n}(\%)\end{array}$ \\
\hline Obsessive compulsive disorder & $18(60)$ & NA \\
Tourette's syndrome & $\mathrm{NA}$ & $1(3)$ \\
Chronic motor tic disorder & $\mathrm{NA}$ & $6(15)$ \\
Major depression & $5(18)^{2}$ & $14(40)^{1}$ \\
$\quad$ Current & $18(64)$ & $30(86)$ \\
Lifetime & $1(7)^{3}$ & $11(31)^{1}$ \\
Generalized anxiety disorder & $14(52)$ & $26(74)$ \\
$\quad$ Current & $8(33)^{5}$ & $12(35)^{4}$ \\
Lifetime & $4(17)^{5}$ & $14(41)^{4}$ \\
Panic disorder, lifetime & $11(39)^{2}$ & $4(12)^{4}$
\end{tabular}

\footnotetext{
${ }^{1} n=35,{ }^{2} n=28,{ }^{3} n=27,{ }^{4} n=34,{ }^{5} n=24$, NA $=$ not applicable.
} 
than either the subjects with a past history of generalized anxiety disorder or those that had no past history of GAD.

\section{Comparisons of CSF Measures across Diagnostic Groups}

As an initial test, a multivariate analysis of variance was performed that included all of the CSF measures as dependent variables and subject diagnosis as the independent variable (using both three-, four-, and fivegroup diagnostic models described above). All three models found a significant effect of diagnosis (threegroup model: $\mathrm{F}[12,172]=4.13, p=.0001$; four-group model: $F[18,241]=3.55, p=.0001$; and five-group model: $F[24,294]=2.81, p=.0001)$.

CSF TYR. The overall comparison of log transformed CSF TYR levels across the three groups revealed significant group differences $(\mathrm{F}[2,100]=5.61, p=.005)$. Post hoc testing indicated that the OCD group had significantly lower $(p<.05)$ levels of CSF TYR than the normal controls (Figure 1A). A similar result was obtained in the four- and five-group comparisons (fourgroup: $F[3,99]=4.33, p=.007$; and five-group:
$\mathrm{F}[4,98]=3.24, p=.02)$. In both the four- and five-group models, the post hoc testing indicated that the OCD patients without tics had significantly lower CSF TYR levels than the normal control subjects $(p<.05)$. Inclusion of current age as a continuous covariate increased the amount of the variance associated with the diagnostic groups for each of the models evaluated. In these analyses, current age was found to be independently associated with CSF TYR. The inclusion of sex in these models did not alter the results of the comparisons across the diagnostic groups. In the all of the models, the OCD patients without tics continued to have significantly $(p<.05)$ lower levels of CSF TYR compared to the normal control subjects.

CSF NE. The overall comparison of log transformed CSF NE levels across the three diagnostic groups revealed significant group differences $(\mathrm{F}[2,94]=8.28, p=$ $.0005)$. As predicted, post hoc testing revealed that the TS group had significantly higher $(p<.001)$ levels of CSF NE than either the normal controls or the OCD patients (Figure 1B). On average, the TS patients had levels of CSF NE that were $55 \%$ higher than the normal controls and $35 \%$ higher than the OCD patients. The overall four- and five-group comparisons were also
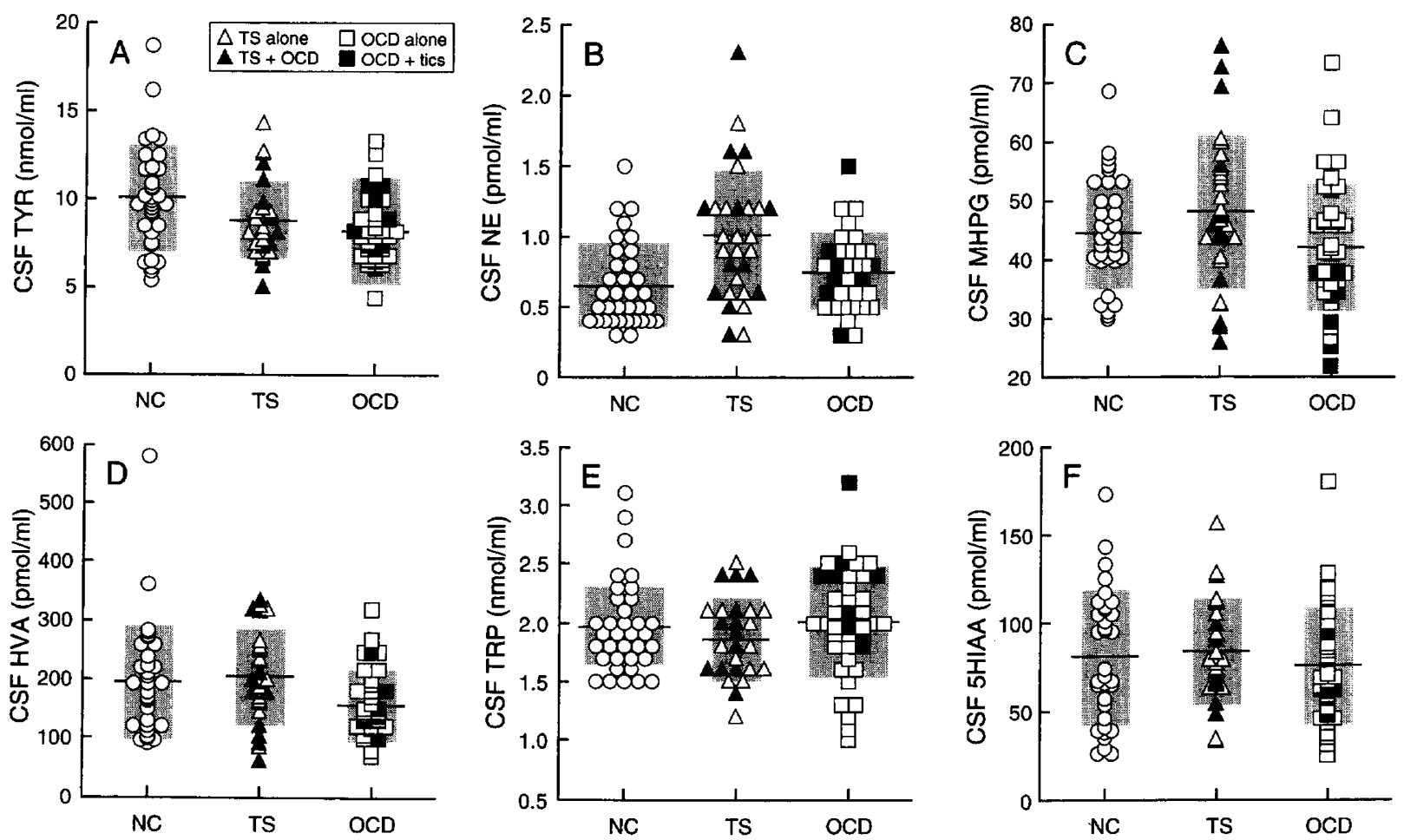

Figure 1. CSF tyrosine (TYR), Norepinephrine (NE), 3-methoxy, 4-hydroxyphenylethylene glycol (MHPG), homovanillic acid (HVA), tryptophan (TRP), and 5-hydroxyindoleacetic acid (5-HIAA) in TS, OCD, and Normal Control Subjects. The OCD and TS groups had significantly lower levels of CSF TYR $(p<.05)$ than the normal controls (A). The TS group had significantly higher levels of CSF NE $(p<.001)$ than either the normal controls or the OCD patients (B). The OCD group had significantly lower levels of CSF HVA $(p<.05)$ than the TS patients, but not the normal controls (D). No mean differences in CSF MHPG, TRP, or 5-HIAA levels were found among the three major diagnostic groups (C, E, and F, see text). 
significant (four-group: $F[3,93]=5.48, p=.0002$; fivegroup: $\mathrm{F}[4,92]=4.57, p=.002)$. In post hoc testing, we found that individuals with full-blown TS, either as a whole or considered separately (TS alone and TS + OCD), had significantly higher $(p<.05)$ levels of CSF NE compared to the normal controls. Individuals with tic-related OCD $(0.78 \pm 0.31 \mathrm{pmol} / \mathrm{ml})$ did not differ significantly from the remaining OCD cases $(0.74 \pm 0.26 \mathrm{pmol} / \mathrm{ml})$. Inclusion of either systolic or diastolic blood pressure as a continuous covariate in the diagnostic group comparisons did not alter the significance of the overall comparisons based on diagnosis. In these analyses, however, diastolic blood pressure $(p=.02)$ was found to be independently related to CSF NE levels. The inclusion of sex in these models did not alter the results of the comparisons across the diagnostic groups.

CSF MHPG. The overall comparison of CSF MHPG levels across the three diagnostic groups approached significance $(\mathrm{F}[2,100]=2.49, p=.09)$ (Figure $1 \mathrm{C})$. The mean CSF MHPG values of the TS patients were higher than those of the other two diagnostic groups. The overall four-group comparison (normals versus TS versus tic-related OCD versus other OCD) was significant $(\mathrm{F}[3,99]=2.72, p<.05)$, with individuals with tic-related OCD having on average lower CSF MHPG than any of the other groups. The overall five-group comparison (normals versus $T S$ alone versus $T S+O C D$ versus tic-related $O C D$ versus other $O C D$ ) was not significant $(F[4,98]=2.02, p<.10)$. Inclusion of percent ideal body weight as a continuous covariate also strengthened the overall three- $(p=.02)$ and four-group ( $p=.04)$ comparisons but did not alter the five-group comparison. The inclusion of sex as a class variable in these models did not alter the results of the comparisons across the diagnostic groups.

CSF HVA. The overall comparison of log transformed CSF HVA levels across the three diagnostic groups revealed significant group differences $(\mathrm{F}[2,98]=3.11, p=$ .05). Post hoc testing indicated that the OCD group had significantly lower $(p<.05)$ levels of CSF HVA than the TS patients but not the normal control subjects (Figure 1D). A similar trend was obtained in the four-group comparison $(\mathrm{F}[3,97]=2.14, p=.10)$ and the five-group comparison $(F[4,96]=1.89, p=.12)$. Inclusion of height as a continuous covariate increased the amount of the variance associated with the diagnostic groups for both the three-group $(\mathrm{F}[3,97]=5.61, p=.001)$, four-group comparisons $(\mathrm{F}[4,96]=4.20, p=.004)$, and five-group comparisons $(\mathrm{F}[5,95]=4.11, p=.002)$. In these analyses, height was found to be independently associated with CSF HVA. In addition, the mean CSF HVA level for the tic-related OCD group was intermediate between the TS and tic-free OCD groups. The inclusion of sex as a class variable in these models did not alter the results of the comparisons across the diagnostic groups.

CSF TRP. The overall comparison of CSF TRP levels across the three groups showed no significant group differences $(F[2,98]=.99, \mathrm{NS})$ (Figure 1E). In contrast, the results of the four- and five-group comparisons were significant (four-group: $\mathrm{F}[3,97]=3.05, p=.03$; fivegroup: $F[4,96]=3.09, p=.02)$. In both the four- and five-group comparisons, the post hoc testing indicated that the OCD patients with tics had significantly higher CSF TRP levels than did any of the remaining groups $(p<.05)$. Inclusion of the subjects' sex or status concerning GAD did not alter these findings (data not shown). However, in these analyses the effect of a current diagnosis of GAD continued to be significant $(p<.05)$.

CSF 5-HIAA. The overall comparison of square root transformed CSF 5-HIAA levels across the diagnostic groups revealed no significant differences (Figure 1F). Inclusion of sex as a class variable or height as a continuous covariate did not alter the findings of the original comparisons across the diagnostic groups.

Ratios of CSF Measures. In an exploratory set of analyses, we also examined the potential value of ratios of various CSF measures to discriminate major diagnostic groups. With the exception of the TYR/TRP ratio, none of the other ratios of CSF measures incrementally increased the amount of the variance associated with the competing diagnostic models. The overall comparison of the log transformed CSF TYR/TRP ratio across the three groups revealed significant group differences $(F[2,98]=8.68, p=.0003)$. Post hoc testing indicated that the OCD group had a significantly lower TYR/TRP ratio $(p<.01)$ than the normal controls or the TS group (Figure 1E). A similar result was obtained in the fourand five-group comparisons (four-group: $F[3,97]=$ $6.17, p=.0007$; five-group: $\mathrm{F}[4,96]=5.20, p=.0008$ ). In univariate analyses across the entire data set, log transformed CSF TYR/TRP ratio was found to be associated with current age $(r=.22, p<.03)$. Inclusion of age as a continuous covariate increased the amount of the variance associated with the diagnostic groups for both the three- $(F[3,97]=9.17, p=.0001)$, four$(\mathrm{F}[4,96]=7.10, p=.0001)$, and five-group comparisons $(\mathrm{F}[5,95]=4.11, p=.002)$. In these analyses, current age was found to be independently associated with the CSF TYR/TRP ratio. Inclusion of sex as a class variable in these models did not alter the results of the comparisons across the diagnostic groups. CSF TRY/TRP was inversely correlated with scores on the HAM-D $(r=$ $-.35, p<.0003)$ and HAM-A $(r=-.42, p<.0001)$. However, inclusion of these variables in ANCOVA comparisons across diagnostic groups did not alter the initial findings reported above (data not shown). This ratio 
was also found to be associated with a comorbid diagnosis of $\operatorname{GAD}(\mathrm{F}[2,85]=5.94, p=.004)$. The inclusion of the patients' status regarding GAD as a class variable did not alter the outcome of the three-, four-, or five-group diagnostic comparisons.

\section{Relationship of CSF Measures to Current Ratings of Tic and Obsessive-Compulsive Symptom Severity}

Analyses were performed to examine the potential relationship between CSF measures of the biogenic amines and clinical ratings of $O C$ and tic symptom severity. If the CSF measure was not normally distributed, Spearman correlations were performed. The only predicted relationship was a positive association of CSF NE and current motor tic severity. A total of 51 correlations were performed for the OC symptom severity ratings with the various CSF measures within either the entire sample or within subgroups of $O C D$ patients (using a Bonferroni adjustment, a $p$ value of less than .001 would be required for significance). For the tic severity ratings, a total of 30 correlations were performed with the various CSF measures within either the entire sample or within the tic disorder patient groups (using a Bonferroni adjustment, a $p$ value of less than .002 would be required for significance).

OC Symptom Severity. TYR was found to be inversely associated with current OC symptom severity in the entire sample (Y-BOCS: obsessions, $r=-.26, p=.01$; compulsions, $r=-.20, p=.04$; total score, $r=-.25$, $p=.01)$. However, this association was not confirmed when either the tic-related $O C D$ or the tic-free $O C D$ samples were considered separately. Indeed, within the tic-free $O C D$ group an association with an opposite sign was found for current compulsions, as measured on the Y-BOCS $(r=.60, p=.002)$.

Across the entire sample, CSF HVA was inversely correlated with ratings of current $O C$ symptom severity (Y-BOCS: obsessions, $r=-.23, p=.03$; compulsions, $r=-.16, p=.11$; total score, $r=-.20, p=.05$ ). However, these associations were only observed in the ticrelated OCD group (Y-BOCS: obsessions, $r=-.34, p=$ .04 ; compulsions, $r=-.31, p=.06$; total score, $r=-.33$, $p<.05)$.

CSF TRP was found to be marginally associated with current OC symptom severity in the entire sample (Y-BOCS: obsessions, $r=.14$, NS; compulsions, $r=.18, p=.08$; total score, $r=.16, p=.10$ ). This association was much stronger in the tic-related OCD group (Y-BOCS: obsessions, $r=.40, p=.01$; compulsions, $r=.39, p=.02$; total score, $r=.42, p=.01$ ) compared to the tic-free OCD group, where none of these correlations were significant.

No correlations were observed between CSF NE, MHPG, or 5-HIAA and clinician severity ratings of ob- sessions or compulsions on the Y-BOCS. We were particularly interested in the possible association between CSF 5-HIAA and obsessions of violence based on our earlier case reports of two individuals in this sample (one with TS and OCD and the other with non-ticrelated OCD) who had very low levels of CSF 5-HIAA (Leckman et al. 1990b). Dichotomizing the sample on the basis of the presence or absence of violent obsessions, however, did not yield a significant result.

CSF TYR/TRP was also found to be inversely associated with current $\mathrm{OC}$ symptom severity in the entire sample (Y-BOCS: obsessions, $r=-.43, p=.0001$; compulsions, $r=-.39, p=.0001$; total score, $r=-.42$, $p=.0001)$. This association, however, was found only in the tic-related OCD group (Y-BOCS: obsessions, $r=-.45, p=.005$; compulsions, $r=-.37, p=.02$; total score, $r=-.44, p=.006$ ) and not in the tic-free OCD group.

Tic Severity. CSF NE was correlated with motor $(r=$ $.44, p=.0002)$ and phonic tics $(r=.38, p=.001)$ in the overall data set. As predicted within the group of individuals with a personal history of tic disorder, there was a trend towards a significant correlation between CSF NE and current severity of motor tics $(r=.31, p<$ .10) but not phonic tics.

CSF TRP was inversely associated with indices of tic severity in the entire sample (YGTSS: motor tics, $r=-.22, p=.09$, phonic tics, $r=-.37, p=.002$; total score, $r=-.27, p=.03$ ). Within the tic disorder group (TS + tic-related OCD), these associations were even stronger, particularly for the phonic tics (YGTSS: motor tics, $r=-.24$, NS; phonic tics, $r=-.74, p=.0001$; total score, $r=-.44, p=.02$ ). No associations were found between current indices of tic severity and CSF TYR, MHPG, HVA, 5-HIAA or the ratio of CSF TYR/TRP.

\section{DISCUSSION}

This study emphasizes the close interrelationship between TS and OCD. Phenomenologically this is reflected in the high rates of comorbidity. In this study, $60 \%$ of the TS subjects were diagnosed with OCD, and $18 \%$ of the OCD patients were diagnosed with either TS or a chronic tic disorder (Table 2). This is a welldocumented observation, with most case series reporting rates of OCD among adult TS cases in the range of $40 \%$ to $80 \%$ (see Leckman 1993 for a review). A recent population-based study found that $42 \%$ of the individuals diagnosed with TS also had OCD (Apter et al. 1993). Less data are available concerning the rates of tic disorders among OCD patients, but the reported rates range from $7 \%$ to $59 \%$ (Rasmussen and Tsuang 1986; Pitman et al. 1987; Leonard et al. 1993; Holzer et al. 1994). 
The high rates of depression and other disorders in OCD and TS are also well-recognized phenomena (Rasmussen and Tsuang 1986; Robertson et al. 1993) that have the potential to confound neurobiological studies. We have addressed this issue by identifying those individuals with current and past comorbid psychiatric diagnoses, by rating the current level of anxiety and depression using well-established clinical rating instruments, and by incorporating this information into the analyses of the CSF data. However, such approaches are necessarily imperfect and caution is warranted in interpreting our results. Comorbid ADHD may well be another important source of variability, particularly in the TS group. However, given the age of our sample, the small number of subjects with a diagnosis of $\operatorname{ADHD}(n=15$, Table 2), and their uneven distribution across the diagnostic groups, we have not been able to examine this question in detail.

With these caveats and limitations in mind, let us consider the CSF data in light of the two hypotheses that motivated this study.

\section{Is Tic-related OCD a Distinct Subgroup of OCD?}

Our CSF data are inconclusive with regard to the question of whether tic-related OCD is a neurobiologically distinct form of OCD. In most instances, the mean CSF levels of the biogenic amines in the tic-related OCD group were either intermediate between the TS and the tic-free OCD groups (CSF TYR and HVA) or closer to the tic-free OCD group (CSF NE, TYR/TRP ratio). The correlational data, however, are more suggestive of the tic-related group being distinct. For example, CSF HVA levels were inversely associated with current ratings of $O C D$ in the tic-related group (partialing out the effects of height, the observed correlation between the Y-BOCS total score and CSF HVA was - .40 $(p=.01)$, whereas this association was not seen in the tic-free $O C D$ group. Similarly, the ratio of CSF TYR/TRP was inversely associated with current ratings of OCD in the tic-related group (partialing out the effects of age, the observed correlation between the Y-BOCS total score and CSF TYR/TRP ratio was $-.40(p=.01))$, but this relationship was not found in the tic-free OCD group. Given the number of correlations performed and their potential instability, however, it is difficult to put much weight on these results.

These data join a growing body of clinical and natural history data (Pitman et al. 1987; George et al. 1993; Holzer et al. 1994; Leckman et al., in press-b), neuroendocrinological data (Hanna et al. 1991; Leckman et al. 1994), and pharmacological data (McDougle et al. 1990, $1993,1994)$ that do support the distinction between ticrelated OCD and non-tic-related or tic-free OCD. Further study is required to resolve these differences, es- pecially because treatment response to SSRIs may be influenced by the relative balance of dopaminergic and serotonergic activity (McDougle et al. 1990, 1993, 1994).

The finding of reduced levels of CSF TYR in OCD compared to normals is intriguing and may relate to the absence of any exacerbation in SSRI-remitted OCD patients following acute TRP depletion (Barr et al. 1944). Given the common transport system for large neutral amino acids including TRP and TYR (Fernstrom et al. 1973; Perez-Cruet et al. 1974), TRP depletion would be expected to increase brain TYR and shift the CSF TYR/TRP ratio in the direction of the normal range.

Heuristically, the observation that dopaminergic neurons become TYR sensitive when they become physiologically active may also be relevant (During et al. 1989). Tyrosine loading or depletion before and after pharmacological trials that alter the intrinsic activity of dopaminergic neurons may prove to be a useful approach to characterize further these putative $O C D$ subtypes (Lehnert and Wurtman 1993).

Our findings are also reasonably consistent with prior CSF studies in OCD in which CSF 5-HIAA was reported to be unchanged (Thorén et al. 1980; Lydiard et al. 1990) or elevated (Insel et al. 1985) compared to normal controls. Although some OCD patients in this sample have both very low CSF 5-HIAA and severe obsessions of violence (Leckman et al. 1990b), we were not able to extend this finding across the entire group of OCD patients with violent obsessions. Future studies that address this issue may want to include prospectively a separate dimensional rating of the severity of violent obsessions as this would permit a more definitive evaluation of the possible association of very low CSF 5-HIAA and obsessions of violence.

CSF studies of TS patients have variously reported CSF HVA to be unchanged (Leckman et al. 1988), reduced (Butler et al. 1979), or elevated (Takano and Ishiguro 1993) compared to normal controls. It may be important to reanalyze these data sets taking into account the presence of OC symptoms in the participating TS patients, given our finding that CSF HVA was found to vary inversely with the severity of $O C$ symptoms.

\section{Do TS Patients Have Elevated Measures of Noradrenergic Activity?}

To our knowledge, this is the first study to report elevated CSF NE levels in TS patients. As such, this report provides further support for the hypothesis that noradrenergic mechanisms are involved in the pathobiology of TS, as first articulated by Cohen et al. (1979). The observed elevation of CSF NE in TS subjects appears to be independent of cardiovascular status, as well 
as of clinical ratings of depression, anxiety, and OC symptoms.

The elevated level of NE in the lumbar CSF reflects the activity of coeruleospinal neurons. In animal studies, these coeruleospinal neurons have been shown to be anteriorly directed collaterals in the midbrain reticular formation (Guyenet 1980). If similar collateral projections are present in humans, increased levels of NE in the lumbar CSF would likely be indicative of increased release of NE in more rostral CNS sites.

The predicted association between CSF NE and motor tic severity was not as robust as expected. This prediction was based on the results from clinical trials in which clonidine was found to be more effective in reducing motor tics than phonic tics (Leckman et al. 1991a). In this population, the four individuals whose CSF NE levels were entirely beyond the normal range all had severe TS. In three of the four cases current motor tic severity was above 18 on the YGTSS (in the severe to extremely severe range). The neuroanatomical basis for the possible relationship between motor tics and central NE activity is unclear. Possible mechanisms include direct effects on the neocortex, which may also play a role in modulating the activity of the corticostriatiothalamocortical (CSTC) circuits that have been implicated in TS (Leckman et al. 1991b; Peterson et al. 1993; Singer et al. 1993). Alternatively, indirect mechanisms may play some role. For example, ascending noradrenergic projections can influence the activity of the CSTC circuits indirectly through their effect on dopamine-containing neurons in the substantia nigra and ventral tegmental area, which in turn innervate striatal, hypothalamic, and mesolimbic areas, as well as the prefrontal cortex (Tassin et al. 1979; Herve et al. 1982; Grenhoff and Svennson 1993; Grenhoff et al. 1993). A similar argument can be made for indirect effects via NE projections to the serotonin containing cells of the dorsal raphe, which in turn project to sites within the CSTC circuits.

The findings with regard to CSF MHPG levels were less robust with only some of diagnostic group comparisons reaching statistical significance. The mean differences, however, were in the predicted direction and CSF MHPG and NE were significantly intercorrelated with the TS sample $(r=0.43, p=.02, n=28)$.

We did not prospectively evaluate the relationship between CSF NE and MHPG levels and response to clonidine treatment. However, based on medical records and patient reports of the TS patients $(n=15)$, we did find a trend $(r=.50, p<.07)$ between CSF NE levels and an individual's responsiveness to clonidine (after partialing out the association between CSF NE and the diastolic blood pressure at the time of the LP).

Previous reports have shown that clonidine and other central $\alpha_{2}$ agonists can dramatically reduce CSF NE levels (Cubeddu et al. 1984; Mefford and Garrick
1989), so that we might expect that those patients with high levels of CSF NE and severe motor tics would benefit the most from clonidine treatment. Further prospective studies of this and related questions are warranted.

The observed correlations between CSF NE and diastolic blood pressures are consistent with previous reports when normotensive and hypertensive patients were taken together (Eide et al. 1979; Cubeddu et al. 1984). However, these relationships appear to be independent of the mechanisms responsible for the elevated CSF NE levels seen among the TS patients in this series.

Although we doubt that alterations in central noradrenergic mechanisms are etiologically responsible for the genetically determined TS vulnerability (Pauls and Leckman 1986; Price et al. 1988), it seems plausible that alterations in the activity of central noradrenergic systems may play an important role in mediating the severity of tic symptomatology over the life span (Leckman et al. 1992). Such alterations may be an important prognostic factor in determining which TS patients go on to have a malignant course in adulthood. Evidence in support of this hypothesis comes from collateral portions of this study, in which we found elevated levels of CSF corticotrophin releasing factor in TS patients compared to normal controls (Chappell et al. in press). We also found that some severely affected TS patients demonstrated a heightened responsivity to the stress of the LP compared to the normal volunteers (Chappell et al. 1994).

The hypothesis that central noradrenergic systems may play an important role in mediating the severity of tic symptomatology over the life span is also consistent with the near-universal observation that tic symptoms increase during periods of stress (Jagger et al. 1982; Bornstein et al. 1990). The observed increased activity of the NE system may also be related to levels of maternal stress experienced during gestation reported by some mothers of severely affected TS patients (Leckman et al. 1990a; Leckman and Peterson 1993).

Other monoamine systems are likely to be involved in the pathobiology of tic disorders (Leckman et al., in press-a; see Singer 1993 for reviews). The robust negative correlation between CSF TRP and phonic tic symptoms is suggestive in this regard. Indeed, including both CSF NE and TRP in a linear regression, it is possible to account for $22 \%$ of the variance (adjusted $r$-square) in motor tics and $58 \%$ of the variance in phonic tics (adjusted $r$-square).

It is well known that neurochemical measurements from the lumbar CSF provide, at best, an imperfect index of central activity. The rich complexity of monoaminergic projections throughout the neural axis including the spinal cord, their circadian rhythms, the potential for right-left differences, as well as rostralcaudal and in some cases caudal-rostral gradients and 
differences in diffusion and transport rates into and out of the CSF from both central and peripheral sources combine to limit severely the interpretability of CSF findings. Indeed, the results of a single tap may not agree well with data from continuous sampling procedures. Despite these limitations, the integrative function of many of the monoaminergic systems in the CNS and ANS may permit some global inferences from CSF measures that may be more precisely explored using ligand-based SPECT and PET studies or measurements based on in vivo MR spectroscopy.

Future studies of the role of biogenic amine mechanisms in TS and OCD, based on continuous sampling techniques of lumbar CSF or imaging-based techniques, may provide important information that can be translated into improved treatment regimens. Such studies may also add to our prognostic acumen and our ability to monitor variables relevant to the long-term outcome of OCD, TS, and related disorders.

\section{ACKNOWLEDGMENTS}

This work was supported by NIH grants MH44843, MH49351, MH00508, NS16648, HD03008, RR00125, and RR06022 (General Clinical Research Centers), MH30929 (Mental Health Clinical Research Center), and the Tourette Syndrome Association. The authors would also like to thank Katrina Artavanis, Taraneh Shafii, and Colin Bondi for their help with the completion of this study and Drs Ann M. Rasmusson, Matthew J. During, Paul J. Lombroso, Robert A. Makuch, Bradley S. Peterson, and Yanki Yazgan for their comments on an earlier draft of this report.

\section{REFERENCES}

Anderson GM, Young JG, Cohen DJ (1979): A rapid liquid chromatographic method for the determination of tyrosine, tryptophan, 5-hydroxyindoleacetic acid and homovanillic acid in cerebrospinal fluid. J Chromatogr 142: 501-505

Anderson GM, Young JG, Batter DK, Young SN, Cohen DJ, Shaywitz BA (1981): Determination of indoles and catechols in rat brain and pineal using liquid chromatography with fluorometric and amperometric detection. J Chromatogr 223:315-320

Anderson GM, Durkin TA, Morton JB, Cohen DJ (1988): Liquid chromatographic determination of urinary catecholamines after one-step alumina extraction. J Chromatog 424:373-377

Ang L, Borison R, Dysken M, David JM (1982): Reduced excretion of MHPG in Tourette syndrome. In Friedhoff AJ, Chase TN (eds), Advances in Neurology: Gilles de la Tourette Syndrome, Vol 35. New York, Raven Press, pp 171-175

Apter A, Pauls DL, Bliech A, Zohar AH, Kron S, Ratzoni G, Dycian A, Kotler M, Weizman A, Gadot N, Cohen DJ (1993): An epidemiological study of Gilles de la Tourette's syndrome in Israel. Arch Gen Psychiatry 50:734-738
Barr LC, Goodman WK, McDougle CJ, Delgado PL, Heninger GR, Charney DS, Price LH (1994): Tryptophan depletion in obsessive compulsive disorder patients responding to serotonin reuptake inhibitors. Arch Gen Psychiatry 51:309-317

Borison RL, Arg L, Hamilton WJ, Diamond BI, David JM (1983): Treatment approaches in Gilles de la Tourette syndrome. Brain Res Bull 11:205-208

Bornstein RA, Baker GB (1992): Urinary amines in adults with Tourette syndrome. Psych Res 43:277-285

Bornstein RA, Stefl ME, Hammond L (1990): A survey of Tourette syndrome patients and their families: The 1987 Ohio Tourette survey. J Neuropsychiatr Clin Neurosci 2:275-281

Butler IJ, Koslow SH, Selfert WE, Caprioli RM, Singer HS (1979): Biogenic amine metabolism in Tourette syndrome. Ann Neurol 6:37-39

Chappell PB, Leckman JF, Bissette G, McSwiggan-Hardin MT, Nemeroff C, Cohen DJ (in press): Elevated levels of CSF corticotrophin releasing factor in Tourette syndrome: Comparison with obsessive compulsive disorder and normal controls. Biol Psychiatry

Chappell PB, Riddle MA, Anderson GM, Scahill LD, McSwiggan-Hardin MT, Walker DE, Cohen DJ, Leckman JF (1994): Enhanced stress responsivity of Tourette syndrome patients undergoing lumbar puncture. Biol Psychiatry $36: 35-43$

Chappell G, Goodman W, Greist J, Jenike M, Rasmussen S, White K, Hackett E, Gaffney M, Bick PA (1990): Results of a double-blind placebo controlled trial of a new serotonin uptake inhibitor, sertraline, in the treatment of obsessive-compulsive disorder. Psychopharmacol Bull 26:279-284

Clomipramine Study Group (1991): Clomipramine in the treatment of patients with obsessive-compulsive disorder. Arch Gen Psychiatry 48:730-738

Cohen DJ, Shaywitz BA, Caparulo B, Young JG, Bowers MB Jr (1979): Chronic multiple tics of Gilles de la Tourette's disease: CSF acid monoamine metabolites after probenecid administration. Arch Gen Psychiatry 35:245-250

Cohen DJ, Young JG, Nathanson JA, Shaywitz BA (1979): Clonidine in Tourette syndrome. Lancet 2:551-553

Cubeddu LX, Hoffmann IS, Davila J, Barbella YR, Ordaz P (1984): Clonidine reduces elevated cerebrospinal fluid catecholamine levels in patients with essential hypertension. Life Sci 35:1365-1371

During MJ, Acworth IN, Wurtman RJ (1989): Dopamine release in rat striatum: Physiological coupling to tyrosine supply. J Neurochem 52:1449-1454

Eide I, Lolloch R, de Quattro V, Miano L, Dugger R, Van der Meulen J (1979): Raised cerebrospinal fluid norepinephrine in some patients with primary hypertension. Hypertension 1:255-260

Fernstrom JD, Larin F, Wurtman RJ (1973): Correlations between brain tryptophan and plasma neutral amino acid levels following food consumption in rats. Life Sci 13: 517-524

George MS, Trimble MR, Ring HA, Sallee FR, Robertson MM (1993): Obsessions in obsessive-compulsive disorder with and without Gilles de la Tourette's syndrome. Am J Psychiatry 150:93-97 
Goetz CG, Tanner CM, Wilson RS, Carroll VS, Como PG, Shannon KM (1987): Clonidine and Gilles de la Tourette syndrome: Double-blind study using objective rating methods. Ann Neurol 21:307-310

Goodman WK, Price LH, Rasmussen SA, Delgado PL, Heninger GR, Charney DS (1989a): Efficacy of fluvoxamine in obsessive-compulsive disorder: A double-blind comparison with placebo. Arch Gen Psychiatry 46:36-43

Goodman WK, Price LH, Rasmussen SA, Mazure C, Fleischmann RL, Hill CL, Heninger GR, Charney DS (1989b): The Yale-Brown Obsessive Compulsive Scale (Y-BOCS): I. Development, use, and reliability. Arch Gen Psychiatry 46:1006-1011

Goodman WK, Price LH, Rasmussen SA, Mazure C, Delgado $P$, Heninger GR, Charney DS (1989c): The Yale-Brown Obsessive Compulsive Scale (Y-BOCS): II. Validity. Arch Gen Psychiatry 46:1012-1016

Goodman WK, Price LH, Degado PL, Palumbo J, Krystal JH, Rasmussen SA, Heninger GR, Charney DS (1990a): Specificity of serotonin reuptake inhibitors in the treatment of obsessive compulsive disorder: Comparison of fluvoxamine and disipramine. Arch Gen Psychiatry 47: $577-585$

Goodman WK, McDougle CJ, Price LH, Riddle MA, Pauls DL, Leckman JF (1990b): Beyond the serotonin hypothesis: A role for dopamine in some forms of obsessive compulsive disorder? J Clin Psychiatry 51:36-43

Grenhoff J, Svennson TH (1993): Prazosin modulates firing pattern of dopamine neurons in the rat ventral tegmental area. Eur J Pharmacol 233:79-84

Grenhoff J, Nisell M, Ferre S, Ashton-Jones C, Svensson TH (1993): Noradrenergic modulation of midbrain dopamine cell furing elicited by stimulation of the locus coerueleus in the rat. J Neural Transmission 93:11-25

Guyenet PG (1980): The coeruleospinal noradrenergic neurons anatomical and electrophysiological studies in the rat. Brain Res 189:121-133

Hamilton M (1959): The assessment of anxiety states by rating. Br J Psychol 32:50-55

Hamilton M (1967): Development of a rating scale for primary depressive illness. Br J Soc Clin Psychol 6:278-296

Hanna GL, McCracken JT, Cantwell DP (1991): Prolactin in childhood obsessive-compulsive disorder: Clinical correlates and response to clomipramine. J Am Acad Child Adolesc Psychiatry 30:173-178

Herve D, Blanc G, Glowinski J, Tassin JP (1982): Reduction of dopamine utilization in the prefrontal cortex but not in the nucleus accumbens after selective destruction of noradrenergic fibers innervating the ventral tegmental area in the rat. Brain Res 237:510-516

Hollander E, Fay M, Liebowitz MR (1988): Clonidine and clomipramine in obsessive-compulsive disorder. Am J Psychiatry 145:1015-1017

Hollander E, DeCaria C, Nitescu A, Cooper T, Stover B, Gully R, Klein DF, Liebowitz MR (1991): Noradrenergic function in obsessive-compulsive disorder: Behavioral and neuroendocrine responses to clonidine and comparison to healthy controls. Psychiatry Res 37:161-177

Holzer J, Goodman WK, Price LH, Bear L, Leckman JF, Heninger GR (1994): Obsessive compulsive disorder with and without a chronic tic disorder: A comparison of symptoms in 70 patients. Br J Psychiatry 164:469-473

Insel TR (1992): Toward a neuroanatomy of obsessivecompulsive disorder. Arch Gen Psychiatry 49:739-744

Insel TR, Mueller EA, Alterman I, Linnoila M, Murphy DL (1985): Obsessive-compulsive disorder and serotonin: Is there a contradiction? Biol Psychiatry 20:1174-1188

Jagger J, Prusoff BA, Cohen DJ, Kidd KK, Carbonari CM, John K (1982): The epidemiology of Tourette's syndrome: A pilot study. Schizophren Bull 8:267-278

Knesevich JW (1982): Successful treatment of obsessivecompulsive disorder with clonidine hydrochloride. Am J Psychiatry 139:360-365

Lake CR, Ziegler MG, Eldridge R, Murphy DL (1977): Catecholamine metabolism in Gilles de la Tourette's syndrome. Am J Psychiatry 134:257-260

Leckman JF (1993): Tourette's syndrome. In Hollander E (ed), Obsessive-compulsive Related Disorders. Washington DC, American Psychiatric Association Press

Leckman JF, Peterson BS (1993): The pathogenesis of Tourette's syndrome: Epigenetic factors active in early CNS development. Biol Psychiatry 34:425-427

Leckman JF, Sholomskas D, Thompson WD, Belanger A, Weissman MM (1982): Best estimate of lifetime in psychiatric diagnosis: A methodologic study. Arch Gen Psychiatry 39:879-883

Leckman JF, Cohen DJ, Gertner JM, Ort SI, Harcherik DF (1984): Growth hormone response to clonidine in children ages 4-17: Tourette syndrome vs. children with short stature. J Am Acad Child Psychiatry 23:174-181

Leckman JF, Ort S, Caruso KA, Anderson GM, Riddle MA, Cohen DJ (1986): Rebound phenomena in Tourette's syndrome after abrupt withdrawal of clonidine. Arch Gen Psychiatry 43:1168-1176

Leckman JF, Riddle MA, Berrettini WH, Anderson GM, Hardin MT, Chappell PB, Bisette G, Nemeroff CB, Goodman WK, Cohen DJ (1988): Elevated CSF dynorphin A[18] in Tourette's syndrome. Life Sci 43:2015-2023

Leckman JF, Riddle MA, Hardin MT, Ort SI, Swartz KL, Stevenson J, Cohen DJ (1989): The Yale Global Tic Severity Scale (YGTSS): Initial testing of a clinician-rated scale of tic severity. J Am Acad Child Adolesc Psychiatry 28:566-573

Leckman JF, Dolansky ES, Hardin MT, Clubb M, Walkup JT, Stevenson J, Pauls DL (1990a): Perinatal factors in the expression of Tourette's syndrome: An exploratory study. J Am Acad Child Adolesc Psychiatry 29:220-226

Leckman JF, Goodman WK, Riddle MA, Hardin MT, Anderson GM (1990b): Low CSF 5HIAA and obsessions of violence: Report of two cases. Psych Res 33:95-99

Leckman JF, Hardin MT, Riddle MA, Stevenson J, Ort SI, Cohen DJ (1991a): Clonidine treatment of Gilles de la Tourette syndrome. Arch Gen Psychiatry 324-328

Leckman JF, Knorr AM, Rasmusson AM, Cohen DJ (1991b): Another frontier for basal ganglia research: Tourette's syndrome and related disorders (letter). Trends Neurosci $14: 94$

Leckman JF, Pauls DL, Peterson BS, Riddle MA, Anderson GM, Cohen DJ (1992): Pathogenesis of Tourette syn- 
drome: Clues from the clinical phenotype and natural history. In Chase TN, Friedhoff AJ, Cohen DJ (eds), Advances in Neurology-Tourette Syndrome: Genetics, Neurobiology, and Treatment, Vol 58. New York, Raven Press, pp 15-24

Leckman JF, Goodman WK, North WG, Chappell PB, Price LH, Pauls DL, Anderson GD, Riddle MA, McSwigganHardin MT, McDougle CJ, Barr LC, Cohen DJ (1994): Elevated levels of CSF oxytocin in obsessive compulsive disorder: Comparison with Tourette's syndrome and healthy controls. Arch Gen Psychiatry 51:782-792

Leckman JF, Pauls DL, Cohen DJ (in press-a): Tic disorders. In Blood FE, Kupfer D (eds), Psychopharmacology: The Fourth Generation of Progress. New York, Raven Press

Leckman JF, Grice DE, Barr LC, de Vries ALC, Martin C, Cohen DJ, Goodman WK, Rasmussen SA (in press-b): Ticrelated vs non-tic-related obsessive compulsive disorder.

Lee MA, Cameron OG, Gurguis GNM, Glitz D, Smith CB, Hariharan CM, Abelson JL, Curtis CG (1990): Alpha-2 adrenoceptor status in obsessive-compulsive disorder. Biol Psychiatry 27:1083-1093

Lehnert H, Wurtman RJ (1993): Amino acid control of neurotransmitter synthesis and release: Physiological and clinical implications. Psychother Psychosom 60:18-32

Leonard HL, Swedo SE, Rapoport JL, Koby EV, Lenane MC, Cheslow DL, Hamburger SD (1989): Treatment of obsessive-compulsive disorder with clomipramine and desipramine in children and adolescents: A double-blind crossover comparison. Arch Gen Psychiatry 46:1088-1092

Leonard HL, Swedo SE, Lenane MC, Rettew DC, Hamburger SD, Bartko JJ, Rapoport JL (1993): A 2- to 7-year followup study of 54 obsessive-compulsive children and adolescents. Arch Gen Psychiatry 50:429-439

Lydiard RB, Ballenger JC, Ellinwood E, Laraia M, Austin F, Fossey M, Krishnan R, Goli V (1990): CSF monoamine metabolites in obsessive-compulsive disorder. Presented as a poster at the American Psychiatric Association meeting, May 5, 1990; New York, NY

McDougle CJ, Goodman WK, Price LH, Delgado PL, Krystal JH, Charney DS, Heninger GR (1990): Neuroleptic addition in fluvoxamine-refractory obsessive compulsive disorder. Am J Psychiatry 146:652-654

McDougle CJ, Goodman WK, Leckman JF, Barr LC, Heninger GR, Price LH (1993): The efficacy of fluvoxamine in obsessive compulsive disorder: Effects of comorbid chronic tic disorder. J Clin Psychopharmacol 13:354-358

McDougle CJ, Goodman WK, Leckman JF, Lee NC, Heninger GR, Price LH (1994): Haloperidol addition in fluvoxaminerefractory obsessive compulsive disorder: A doubleblind, placebo-controlled study in patients with and without tics. Arch Gen Psychiatry 51:302-308

McKeith IG, Williams A, Nichol AR (1981): Clonidine in Tourette syndrome. Lancet 1:270-271

Mefford IN, Garrick NA (1989): Effects of xylazine on cerebrospinal fluid catecholamines in the rhesus monkey. Brain Res 492:377-380

Müller N, Putz A, Klages U, Hofschuster E, Straube A, Ackenheil M (1994): Blunted growth hormone response to clonidine in Gilles de la Tourette syndrome. Psychoneuroendocrinology 19:335-341
Pauls DL, Hurst CR (1987): Schedule for Tourette's Syndrome and Other Behavioral Syndromes. New Haven, CT: Yale University Child Study Center, Revised

Pauls DL, Leckman JF (1986): The inheritance of Gilles de la Tourette syndrome and associated behaviors: Evidence for autosomal dominant transmission. N Engl J Med 315:993-997

Pauls DL, Raymond CL, Stevenson JM, Leckman JF (1991): A family study of Gilles de la Tourette syndrome. Am J Hum Genet 48:154-163

Perez-Cruet J, Chase TN, Murphy DL (1974): Dietary regulation of brain tryptophan metabolism by plasma ratio of free tryptophan and neutral amino acids in humans. Nature 248:693-695

Peterson BS, Riddle MA, Cohen DJ, Katz LD, Smith JC, Hardin MT, Leckman JF (1993): Reduced basal ganglia volumes in Tourette's syndrome using three-dimensional reconstruction techniques from magnetic resonance images. Neurology 43:941-949

Pigott TA, Pato MT, Bernstein SE, Grover GN, Hill JL, Tolliver TJ, Murphy DL (1990): Controlled comparisons of clomipramine and fluoxetine in the treatment of obsessive-compulsive disorder. Arch Gen Psychiatry 47: 926-932

Pitman RK, Green RC, Jenike MA, Mesulam MM (1987): Clinical comparison of Tourette's disorder and obsessivecompulsive disorder. Am J Psychiatry 144:1166-1171

Price RA, Pauls DL, Druger SD, Caine ED (1988): Family data support a dominant major gene for Tourette syndrome. Psychiatry Res 24:251-261

Rasmussen SA, Tsuang MT (1986): Clinical characteristics and family history in DSM-III Obsessive-compulsive disorder. Am J Psychiatry 143:317-322

Rasmussen SA, Goodman WK, Woods SW, Heninger GR, Charney DS (1987): Effects of yohimbine in obsessivecompulsive disorder. Psychopharmacology 93:308-313

Robertson MM (1989): The Gilles de la Tourette syndrome: The current status. Br J Psychiatry 154:147-169

Robertson MM, Channon S, Baker J, Flynn D (1993): The psychopathology of Tourette's syndrome: A controlled study. Brit J Psychiatry 162:114-117

Siever LJ, Insel TR, Jimerson DC, Lake CR, Uhde TW, Aloi J, Murphy DL (1983): Growth hormone response to clonidine in obsessive-compulsive patients. Br J Psychiatry 142:184-187

Silverstein F, Smith CB, Johnston MV (1985): Effect of clonidine on platelet alpha 2-adrenoreceptors and plasma norepinephrine of children with Tourette syndrome. Devel Med Child Neurol 27:793-799

Singer HS, Tune LE, Butler IJ, Zaczek R, Coyle JT (1982): Clinical symptomatology, CSF neurotransmitter metabolites, and serum haloperidol levels in Tourette syndrome. In Friedhoff AJ, Chase TN (eds), Advances in Neurology: Gilles de la Tourette Syndrome, Vol 35. New York, Raven Press, pp 177

Singer HS, Reiss AL, Brown JE, Aylward EH, Shih B, Chee E, Harris EL, Reader MJ, Chase GA, Bryan RN, Denkla MB (1993): Volumetric MRI changes in basal ganglia of children with Tourette's syndrome. Neurology 43:950956 
Society of Actuaries (1959): Build and Blood Pressure Study. Chicago, IL, Author, pp 16

Swedo SE, Leonard HL, Kruesi MJP, Rettew DC, Listwak SJ, Berrettini W, Stipetic M, Hamburger S, Gold PW, Potter WZ, Rapoport JL (1992): Cerebrospinal fluid neurochemistry in children and adolescents with obsessive-compulsive disorder. Arch Gen Psychiatry 49:29-36

Takano K, Ishiguro T (1993): A study of clinical pictures and monoamine metabolism of Gilles de la Tourette syndrome. Psych Neurol Japonica 95:1-29

Tassin JP, Lavielle S, Herve D, Blanc G, Thierry AM, Alvarez
C, Berger B, Glowinski J (1979): Collateral sprouting and reduced activity of the rat mesocortical dopaminergic neurons after selective destruction of the ascending noradrenergic bundles. Brain Res 4:1569-1582

Thorén P, Asberg M, Bertilsson L, Mellstrom B, Sjoqvist, Traskman L (1980): Clomipramine treatment of obsessivecompulsive disorder: II. Biochemical aspects. Arch Gen Psychiatry 37:1289-1294

Zohar J, Insel TR (1987): Obsessive-compulsive disorder: Psychobiological approaches to diagnosis, treatment, and pathophysiology. Biol Psychiatry 22:667-687 